\title{
Urban consolidation centre - a literature review, categorisation, and a future research agenda
}

Maria Björklund and Henrik Johansson

The self-archived postprint version of this journal article is available at Linköping University Institutional Repository (DiVA):

http://urn.kb.se/resolve?urn=urn:nbn:se:liu:diva-151808

N.B.: When citing this work, cite the original publication.

Björklund, M., Johansson, H., (2018), Urban consolidation centre - a literature review, categorisation, and a future research agenda, International Journal of Physical Distribution \& Logistics Management, 48(8), 745-764. https://doi.org/10.1108/IJPDLM-01-2017-0050

Original publication available at:

https://doi.org/10.1108/IJPDLM-01-2017-0050

Copyright: Emerald

http://www.emeraldinsight.com/ 


\title{
Urban consolidation centre -a literature review, categorisation, and a future research agenda
}

\begin{abstract}
Purpose: Urban consolidation centre (UCC) is a popular initiative targeting the challenge of negative environmental and social impacts from freight transports in cities. Despite this, UCC often fails in practice, which indicates a knowledge gap. Furthermore, research within the field can be described as fragmented, transdisciplinary, and fast-growing. This paper aims to provide an overview of the field by describing dominant categories and themes within the area, identify gaps in order to propose a future research agenda, and provide insights into the needs of practitioners.

Research approach: A systematic literature review targeting journal articles based on UCCs has been constructed with a supplementary snowball approach. A content analysis was performed to categorise themes in the research on UCCs and to identify research gaps, both within and outside the categories identified.
\end{abstract}

Findings and originality: Despite substantial research on UCC, very little research ends up in academic journals. Fifty-six articles address UCC. The most common topics were the role of stakeholders, design of distribution structures and transport resources, environmental and social consideration, and economic considerations. Much focus is directed towards finding "optimal" solutions and designs for potential initiatives with very little, if any, consideration to financial viability or the management of the UCC initiative.

Research impact: This research points out existing gaps in the literature and proposes a future research agenda with UCCs as the focus. For example, although environmental and social arguments are often applied to justify the implementation of UCCs, few studies measure or evaluate their impact. Another important research gap is the economical consideration, both how to generate revenue and how to consider economies of scale.

Practical impact: The practical contribution of most studies is directed towards municipalities. Few findings are presented in a way to support companies. Additionally, by bridging the gaps related to how stakeholders can collaborate and describe what is happening in a UCC, practitioners can use such information as guidelines.

Originality: The results provides a research agenda for the fragmented research targeting urban consolidation centres, supporting the viability of future initiatives.

Key words: urban consolidation centre, systematic literature review, city logistics, urban freight, content analysis. 


\section{Introduction}

Due to ongoing urbanisation, the world's cities are expanding, further stressing an already pressured system (United Nation, 2014). Due to this expansion, the demand for goods will continue to increase, worsening challenges such as congestion, noise, emissions, and safety (Allen et al., 2015). However, the demand for goods is a prerequisite for living and prosperous cities. There is a need to identify viable solutions to alleviate these challenges. Logistic activities, such as transportation, consolidation, and distribution of goods in cities, can be aggregated under the term 'city logistics' (see the definition from Awasthi and Chauhan, 2012). Examples of city logistics initiatives, that aims to reduce this negative impact, include night deliveries or off-peak deliveries (Holguín-Veras et al., 2011), pack stations for parcels (Quak et al., 2014), and urban consolidation centres (UCC) (Browne et al., 2005).

UCCs are one of the most frequently implemented and studied city logistics initiatives (Lagorio et al., 2016; Skjoett-Larsen, 2000; Benjelloun and Crainic, 2009; van Rooijen and Quak, 2010). UCCs have the potential to reduce the environmental and social challenges of urban freight but can also potentially improve the efficiency of distribution systems and enable a change to more environmentally friendly vehicles (Allen et al., 2012). The UCC initiative can be seen as a system including both a logistics facility for consolidation placed in a city area, where different logistics service providers (LSPs) drop off their goods, and the outbound transport system executing the deliveries to receivers in the urban area. UCCs can also perform activities such as storage and pre-retail activities (inspired by van Rooijen and Quak, 2010; Benjelloun and Cranic, 2009; Browne et al., 2005).

Although UCCs were implemented and targeted by researchers as early as the 1970s (Allen et al., 2012; Paddeu, 2017) and have been addressed in a growing number of journal publications (e.g. Lagorio et al., 2016), an overview of research focusing on this particular solution is lacking. Research on UCCs can be described as fragmented and transdisciplinary targeting different areas, such as design and management of the distribution structure (Browne et al., 2011), modelling (Awasthi and Chauhan, 2012), stakeholder management (Nordtømme et al., 2015), and cost and benefit analysis (Browne et al., 2007). As the fragmented field continues to grow, it is important to provide an overview of the field and the knowledge available. Despite the potential benefits that UCC initiatives can provide, the implementation in practice commonly fails (Browne et al., 2005; Nordtømme et al., 2015). This points to the presence of severe knowledge gaps. The reasons behind these failures are not described as being transport related. Already in 2005, Dablanc (2005) argued that one explanation for the failures of UCCs is the lacking of recognition that the delivery involves other aspects than transport related aspects such as administration and commercial. Instead, there is a need to expand the scope of research on UCCs to include other aspects, such as addressing the area from a business perspective and taking into account financing, commercial concerns, and management (Benjelloun et al., 2010; Malhene et al., 2012; Nordtømme et al., 2015). The need to identify these gaps is central to guiding future research and targeting the knowledge needs of practitioners. In response to this need, the present study poses the following purpose: provide a systematic literature review of journal articles focusing on the UCC initiatives; describe dominant categories and themes within the area; and identify gaps in order to propose a future research agenda and provide insights into the needs of practitioners. 


\section{Method}

A Systematic Literature Review (SLR) methodology was selected. An SLR, in line with the purpose of this study, provides several strengths in identifying and summarising common areas in a field, contrasting the differences, assessing the existing intellectual territory, identifying research gaps, and providing particular and concrete propositions for a future research agenda (Tranfield et al., 2003; Crowther and Cook, 2007; Denyer and Tranfield, 2009; Saenz and Koufteros, 2015). Reviews can also provide insights and guidance into the needs of practitioners and policy makers (Tranfield et al., 2003; Denyer and Tranfield, 2009). The phases of the entire SLR process are presented in Figure 1, the creation of which was largely guided by Crowther and Cook (2007), Denyer and Tranfield (2009), and Tranfield et al. (2003). Following this structural path as opposed to a more narrative literature review results in clear findings with a high level of transparency.

The researchers started out by defining a clear topic: articles focused on UCC solutions. Thus, the process was aimed at identifying articles targeting terminals that serve cities or city areas, and that includes shipments from different shippers and carriers within the same vehicle (in line with the UCC definition by Benjelloun and Crainic, 2009). Durach et al. (2017) put forward the importance of having a clearly defined unit of analysis early in the process of conducting a SLR within the area of supply chain management. The unit of analyses in this study were articles that include both the UCC (i.e. the terminal) and the outbound distribution (i.e. transports from the UCC to the receivers). UCC and its synonyms were used as search terms instead of broader terminology such as "consolidation terminals". The identification and selection of search terms, were guided by the recommendation to use appropriately specific search terms (Crowther and Cook, 2007). We aimed to include, for example, "city distribution centre", as the term applied by Benjelloun and Cranic (2009). Browne et al. (2005) and Wolpert and Reuter (2012) provided two separate lists of synonyms to urban consolidation centre that were used as a base for identifying search terms. Some terms were excluded, such as "logistic centre" and "offsite logistics support concept", as they were too general and resulted in too many articles not related to city logistics. During the read-through, a new synonym, "freight consolidation centre", was found and added to the search. To further ensure that all relevant synonyms were found, new synonyms were asked for when a very preliminary version of this paper was presented at a logistics research conference. However, no additional synonym was identified. Minor changes were made to include both American and English spellings, as well as adding an asterisk to include alternates such as both singular and plural forms. Also, if the term included either "urban" or "city", both were applied, as these are commonly used as synonyms. All search terms applied are listed in Table 1, and the search was conducted in the titles, abstracts, and key words sections, inspired by an approach used by e.g. Wong et al. (2013).

It is worth noticing the importance of including the right search terms in this kind of study. The last added search term, "freight consolidation centre", was found in one of the papers and used in a complementary search. Guided by Denyer and Tranfield (2009), regarding the importance that the protocol does not restrict the review and the importance to alter the plan, if needed, we adjusted the search string by adding this search term. This search resulted in five new articles, all relevant for this study and, thus, included in the final scope. This also made us aware to look for other search terms during the entire process.

\section{Insert Table 1}

Table 1: All search terms included in the scan. 
We aimed to limit the literature search as little as possible, but at the same time, we strove to maintain a high level of quality in the identified papers. For example, the study was not limited with regard to specific journals, publication year, or methods applied, meaning results such as conceptual papers not providing new empirical data were included.

The databases Scopus, Web of Science, and Business Source Premier were selected, as they cover a sizable portion of city logistics literature. Only peer-reviewed journal articles were considered, as the selected literature then ensured a high quality and consistency between themes and sources (e.g. Touboulic and Walker, 2015). The strategy of only using peerreviewed articles in SLR is common within logistics (e.g. Carter and Liane Easton, 2011; Mangiaracina et al., 2015; Meixell and Luoma, 2015). However, applying this limitation was a difficult decision, as The Procedia of Social and Behavioural Science, which publishes articles from one of the leading conferences within the field (International Conference on City Logistics), did not have articles classified as peer reviewed by the literary databases.

The search resulted in 138 hits in the Scopus database, of which 68 articles in academic journals or articles in press. Subject areas like medicine, dentistry, and neuroscience were excluded, which further narrowed the result down to 63 articles. The last delimitation was to exclude all articles not written in English, leaving 54 articles. The same procedure was repeated in the databases Web of Science and then Business Source Premier, which resulted in an additional seven articles and zero articles, respectively; thus, 61 articles in total. Both authors individually read the abstracts of these articles and excluded those that were not focused on, but more exemplified or mentioned, the topic of a UCC solution. A large consensus between the authors' lists was present, since most excluded articles focused on areas clearly outside the scope of this study. The few papers on which the authors did not agree were discussed until an agreement was reached, as suggested by Crowther and Cook (2007). After the abstract reading, 50 articles remained. These articles were read in full by both researchers (as suggested by Crowther and Cook, 2007). To be included in the final sample, the article had to consider UCCs extensively. For example, an article about optimising the route from a UCC that only mentioned UCCs, but could have described any milk route, was excluded. However, if the articles included specifics, such the cost of UCCs, they were included. After the read-through of the entire articles, 48 remained. The authors also classified the articles in "more or less relevant" categories. Relevant articles were studies in which UCCs were the main focus, meaning the purpose of the study and/or the empirical data were related to UCCs. This classification was a basis for a supplementary manual review of the references of the most relevant articles, as suggested by Crowther and Cook (2007). In this review, a snowball approach of the references was applied to the "more relevant" articles to identify peer-reviewed journal papers that may have been missed. This review resulted in an identification of an additional 50 articles of potential interest. The same narrowing process was applied, resulting in the eventual addition of eight articles. To ensure traceability, all 56 articles are referenced in chapter 4 and can, thereby, be found in the reference list.

The strategy for analysing the articles in order to identify categories and sub-categories (termed themes in the rest of the article) was largely guided by the principles of content analysis, as both a coding schedule (database to record the coded data) and a coding manual (instruction to support the coding) were applied, both influenced by Bryman and Bell (2015). Common areas were identified based on domination. An inductive approach was applied in the identification to not determine the areas in advance. First, the authors each read about half of the papers individually and inductively defined lists of potential areas based on aspects more commonly addressed in the articles. The exact terminology used in the articles was of secondary importance in the identification of potential areas. Separate databases were used in Microsoft Excel to provide examples/citations of the potential areas identified as well as 
descriptive information regarding the articles. The lists were then compared, and the authors discussed how the different areas could be classified as categories or themes. The differences in the Excel sheets were then discussed until a consensus was reached. The separate sheets were quite similar regarding potential categories, and most of the discussion addressed which main categories should exist and which could be described as themes. The Excel sheets were merged into one. The researchers then read the other half of the articles and discussed the need for minor adjustments regarding the exclusion or inclusion of more themes.

The type of descriptive information to include (e.g. journal title, year of publication, method applied, whether new empirical data was presented) was decided on prior to analysing the articles and selected as it further supported the aim of this paper.

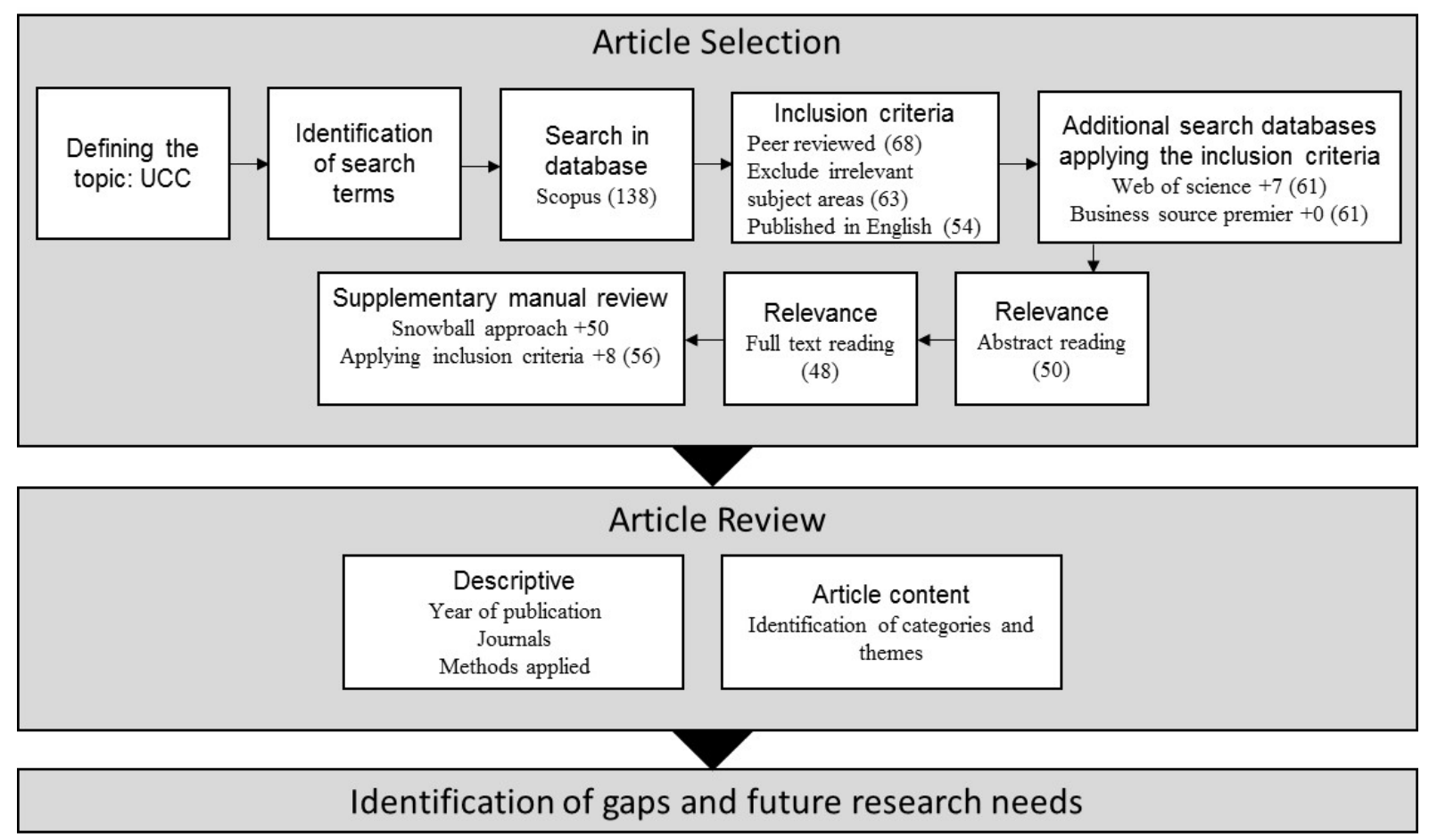

Figure 1: Systematic literature review process.

\section{Descriptive analysis of the reviewed articles}

The year of publication among the identified journals vary from 2000 to 2017, with more than half of the articles published during the last three years, indicating that the area is under significant recent expansion. The oldest article identified is from the year 2000, suggesting the field is quite new from a research point of view.

The substantial number of journals and journal types (e.g. transportation journals, $\mathrm{SCM} /$ logistics journals, other economics journals, and modelling journals) in which the articles have been published clearly indicates that the UCC field can be described as both fragmented and transdisciplinary (see Table 2 for a list of journals). 24 of the journals only have one paper on UCC, while two journals have six.

\section{Insert Table 2}

Table 2: Number of papers per journal. 
The methodological domains, such as case studies, surveys, and modelling, of the reviewed articles is of interest when identifying future research needs (Saenz and Koufteros, 2015). Previous SLR in the field of logistics shows numerous ways to classify the methods selected, such as case or survey studies (Gimenez and Tachizawa, 2012); quantitative, qualitative, mixed methods, theoretical, literature/secondary empirical data, and descriptive (Hoejmose and Adrien-Kirby, 2012); analytical (conceptual/mathematical/statistical), empirical (experiment, cases), and literature reviews (Pilbeam et al., 2012); or quantitative/modelling, case studies/interviews, literature/systematic reviews, empirical/piloting, and questionnaires/surveys (Lagorio et al., 2016). Inspired by this and the combinations applied in the articles studied, the methodologies were classified as: mathematical modelling (including optimisation and simulation), case studies (mostly qualitative), reviews, conceptual papers, and experimental methods. Most common is mathematical modelling, followed by case studies. As some articles used several methods, the number of articles presented in Table 3 is greater than the number of articles identified.

\section{Insert Table 3}

Table 3: Methods applied in the articles.

Several of the articles are based on secondary data. The type of empirical data used in the articles is presented in Table 4. Moreover, some countries are strongly overrepresented in terms of empirical data in this area, such as Italy (Rome, Parma, Como, Vicenza, Turin), Great Britain (London, "20 cities in GB", Southampton), and Belgium/the Netherlands (Brussels, Hasselt, Groningen).

\section{Insert Table 4}

Table 4: Type of empirical data related to the number of articles.

\section{Description of categories identified}

This chapter aims to address the first part of the purpose of this study, to describe dominant categories and themes within the area of UCC.

Five dominant categories were identified among the reviewed articles. For each category, a number of themes were identified. Table 5 shows the distribution of the reviewed papers in categories and themes.

\section{Insert Table 5}

Table 5: Categories and themes in the reviewed articles.

\section{Category 1: Stakeholders}

UCCs are commonly described as influencing and involving different stakeholders (e.g. Allen et al., 2012), and "Stakeholders" became the first category identified. Five stakeholder groups were identified in the articles studied: local authorities/government, receivers, LSP, suppliers, and others (less commonly mentioned stakeholders, such as UCC operators, residents, and research institutes). Four themes were identified within the stakeholder category: the articles that, on a more general basis, mention stakeholders that can be influenced or affected by UCCs; stakeholders who are part of the UCC's organisation; stakeholders who have taken an 
active part in supporting research on UCCs by, for example, contributing with empirical data; and finally, stakeholders who are targeted in the practical implications and contributions of the research.

Commonly mentioned stakeholders are local authorities, LSPs, and receivers (e.g. Awasthi and Chauhan, 2012; Cherrett et al., 2012). In Österle et al. (2015), these three stakeholders were described and put forward as capable of implementing city logistics initiatives.

Multiple articles highlighted the importance of including different stakeholders during the process of establishing a UCC (Ambrosini et al., 2013; Gonzalez-Feliu et al., 2014a; Nordtømme et al., 2015; Österle et al., 2015). Gonzalez-Feliu et al. (2014a) distinguished between private and multi-user UCCs, stating that it is often easier to operate a single user UCC, which is also in line with Zunder and Ibanez (2004). Multiple articles pointed out the importance of sharing costs and benefits (e.g. Ambrosini et al., 2013; Gonzalez-Feliu et al., 2014a; Triantafyllou et al., 2014) and having common goals (Österle et al., 2015). Another example concerns how groups of stakeholders are organised; Nordtømme et al. (2015), for example, mentioned partnerships.

Several stakeholders take part in and contribute with information to the research studies. Local authorities, LSPs, and receivers are the most recurring groups involved. The LSPs provided information regarding routs (see e.g. Awasthi et al., 2011), local authorities participated in workshops (Nordtømme et al., 2015), or receivers provided perspective on different measures (dell'Olio et al., 2017; Johansson and Björklund, 2017; Paddeu, 2017).

Studies described practical contributions directed towards LSPs (e.g. Olsson and Woxenius, 2014), local authorities (Battaia et al., 2014; Österle et al. 2015), UCCs (Teo et al., 2015; Ji et al., 2017), or several stakeholder groups simultaneously, such as carriers, operators, authorities, residents (Zhou and Wang, 2014). In some studies, it is clear to whom the findings are directed, even without detailed description; for example, when investigating regulations or fees which are actions that the municipality can take (see e.g. Awasthi and Chauhan, 2012).

\section{Category 2: Design of distribution structures}

As the implementation of a UCC results in a changed distribution pattern, the design of distribution structures was addressed in a majority of the articles. The articles described the changes in design as changed localisation of a UCC, and/or as changed routes.

A wide range of aspects in the selection of location was considered in the articles. Furthermore, different methods were applied. Gianessi et al. (2016) and Sopha et al. (2017) used mathematical models to consider the influence of location on cost. Rao et al. (2015) considered economic, social, and environmental aspects in their optimisation model, and concluded that, when all three aspects are in play, a UCC should be located outside the city. Crainic et al. (2004) elaborated on a system with UCCs and satellites in which the satellites could be located in parking lots or at bus depots. Teo et al. (2015) used the following criteria when considering locations for a UCC applying simulation: not within the city area, and in proximity to a well-connected road with links to LSP terminals. In the same way, Janjevic et al. (2013) highlights the importance UCC accessibility both upstream and downstream. Based on mathematical modelling Awasthi et al. (2011) emphasised the significance of location planning for distribution cost savings and minimizing congestion. In addition, Browne et al. (2007) addressed congestion when discussing the location of the UCC. Chen et al. (2012) modelled how location influence factors, such as rent cost and outbound trip distance. 
Route planning and optimisation are the second theme identified. Escuín et al. (2012) compared a traditional distribution system with and without a UCC with a vehicle routing model, analysing distance travelled and travel time. Travel distance, together with factors such as number of trips, was also a central parameter in Cattaruzza et al. (2016)'s optimisation model. Pamučar et al. (2016) used parameters such as environment, health, use of space, and logistics cost. Li et al. (2016) also addressed the environmental aspect by striving to minimise $\mathrm{CO}_{2}$ emissions per ton-kilometre.

\section{Category 3: Design of transport resources}

The design of transport resources was mentioned in several of the oldest articles (ranging from 2000-2007), indicating that this category has been present longer than the other categories. The areas addressed are closely interlinked; for example, a change of fuel often also includes a change in the transport vehicle, and thereby, vehicle size. The decision process finally yielded the following two themes: change in vehicle fuel (often also including changes in, for example, engines used and vehicle size); and intermodal transports.

A change to electric vehicles (see e.g. Dablanc, 2007; Gianessi et al., 2016; Lebeau et al., 2017) or hybrids with both an electric motor and a diesel motor (e.g. Alessandrini et al., 2012; Escuín et al., 2012) was the most common suggestions among the studies, although some articles considered other vehicle fuels, such as natural gas. Crainic et al. (2004) stated that the vehicles used ought to be small vehicles adapted for operations within urban zones with "clean" energy sources, such as electronic or hydrogen. Lebeau et al. (2013) concluded that the capacity of electric batteries will probably be sufficient when a route originates from a UCC; furthermore, the study simulated the number of deliveries, revealing a potential increase of deliveries due to the more limited payload of the smaller electric vans. Browne et al. (2011) also mentioned that the total delivery distance might increase using electric vehicles. Kawamura and $\mathrm{Lu}$ (2007) modelled different vehicle sizes to test the cost effectiveness of a UCC system. In Browne et al. (2007), large goods vehicles on direct deliveries were replaced by smaller vehicles, resulting in reduced noise and increased use of alternative fuel.

A UCC can facilitate a modal change to e.g. bicycles (e.g. Browne et al., 2011; Staricco and Brovarone, 2016; Estrada and Roco-Riu, 2017) for its outbound transport (i.e. the transports in the urban area) and for the inbound transport (i.e. transports to or from the city area) a change to railway (e.g. Alessandrini et al., 2012; Ambrosini et al., 2013).

\section{Category 4: Environmental and social considerations}

UCC are widely known to contribute to environmental and social sustainability. Two themes were identified under which sustainability is considered: as an argument to why actions need to be taken, and as an explanation of how implementing a UCC changed sustainability.

Several authors describe the implementation of a UCC as a means to improve the attractiveness of the city, including reduced emission, congestion, and noise (e.g. Munuzuri et al., 2005; Bakos et al., 2012; Yang et al., 2015; Björklund et al., 2017).

The changes in environmental and social dimensions range from exact measurements (e.g. Browne et al., 2011; Tozzi et al., 2014; Teo et al., 2015; Cerutti et al., 2016) to unquantified statements (e.g. Browne et al., 2007). A common approach is analysing environmental and social effects in models (e.g. Awasthi and Chauhan, 2012; Rao et al., 2015; Teo et al., 2015). However, a change to the use of UCCs are not always positive for the environment or society. Some factors, such as total distance travelled, may increase with use of a UCC (see e.g. Browne et al., 2011; Lin et al., 2014). 


\section{Category 5: Economic considerations}

The themes identified are: how a UCC affects the economy as a cost driver, or as a means to reduce costs; how UCCs facilitate the economies of scale; and who should finance the UCC.

The economical aspect is in some articles considered in more general terms, such as mentioning costs (e.g. Danielis et al., 2010; Cherrett et al., 2017), while other articles put forward different cost elements (e.g. Lin et al., 2014; Janjevic and Ndiaye, 2017). Examples of cost drivers in the articles are cost for personnel/labour (Browne et al., 2011; Lin et al., 2014; Rao et al., 2015), electricity and power (Lin et al., 2014), land (Gonzalez-Feliu et al., 2014b; Rao et al., 2015), increased administration and handling (Marcucci and Danielis, 2007; Escuín et al., 2012), the building (Browne et al., 2011), rent (Lin et al., 2014; Zhou and Wang, 2014), and maintenance of the facility (Lin et al., 2014). It is common to split up the costs into investment costs and operational costs (e.g. Browne et al., 2011; Morganti and Gonzalez-Feliu, 2015; Sopha et al., 2017). Due to consolidation, a UCC can facilitate more efficient outbound transports and, thereby, reduce costs such as fuel, insurance, maintenance, and driver costs (Browne et al., 2011; Nordtømme et al., 2015).

Large scale (economies of scale) is commonly described as necessary to generate enough income for a UCC to be viable. Several ways to reach economies of scale are put forward, such as high density of receivers (Paddeu et al., 2017; Triantafyllou et al., 2014; Finnegan et al., 2005), high number of LSPs (Ville et al., 2013), and a sufficient number of products passing through the UCC (Allen et al., 2014; Finnegan et al., 2005).

Potential financiers of a UCC can be divided into three groups: funding from local authorities/government (e.g. Zhou and Wang, 2014; Morganti and Gonzalez-Feliu, 2015; Lebeau et al., 2017), commercial financing (e.g. Allen et al., 2014), or both (Triantafyllou et al., 2014; Teo et al., 2015). When considering commercial funding, LSPs and receivers are most commonly mentioned. Allen et al. (2014) pointed out a critical success factor: the sharing of costs between affected stakeholders. Opinions of who should finance a UCC differ; however, several articles pointed to the stakeholder gaining benefits from a UCC, suggesting they should be a part of its financing (Browne et al., 2007; Chen et al., 2012; Allen et al., 2014).

\section{Identified research gaps in the categories}

This chapter aims to address the second part of the purpose: to identify gaps. The gaps are a crucial point of departure for both the development of a future research agenda and insights into the needs of practitioners. The identification of the gaps is based on an elaboration regarding what we did not find in the reviewed articles. The consequences of the gaps are then further discussed and explained to deepen the understanding with regard to the need to bridge these gaps. The chapter describes and discusses the gaps identified within each of the dominant categories. This is followed by a chapter about the gaps that were found, in part, outside the categories, for example, the type of data and the methodology used.

\section{Gaps in Stakeholders}

Even if stakeholders were one of the most obvious categories identified, several articles did not include stakeholders at all. Furthermore, many articles didn't clarify to which stakeholders the managerial or practical implications are directed, if these implications were considered at all. In an article with the purpose of optimising a UCC's location, the inclusion of stakeholders might be of less relevance (e.g. Rao et al., 2015; Muñoz-Villamizar et al., 2014). However, by not involving stakeholders in the studies, the question arises whether the whole picture is being captured. This can be viewed as a gap, since the opinions and concerns from 
affected stakeholders are disregarded; as an example, the location of a UCC might not be optimal for the larger distribution system. In addition, stakeholders' willingness to participate in the change can be lowered, as they are not given an opportunity to affect the solution. It is, therefore, important to include the view from the stakeholder's perspective, both in the process and in order to avoid, for example, sub-optimisations.

Even if stakeholder collaboration is commonly mentioned (e.g. Nordtømme et al., 2015; Browne et al., 2007), none of the studied articles went into detail describing this collaboration. Managing a large number of stakeholders with different goals, costs, and benefits of using a UCC is a challenging task. Despite this, the present research provides very little guidance to practitioners regarding this issue. To what extent poor collaboration between stakeholders can be a reason behind frequent failures of UCCs is an important question not yet addressed in the literature. As UCCs affect multiple stakeholders, it is important to investigate how these collaborations can be formed as well as which important stakeholders should be included in such collaboration.

Three stakeholder groups are often overlooked regarding inclusion in studies: residents, shippers, and UCC operators. Although residents are put forward as one of several stakeholder groups in city logistics (Nordtømme et al., 2015), the residents were seldom mentioned in the articles. Residents are one of the stakeholder groups that ought to gain most from the environmental and safety improvements a UCC can result in. One explanation for the lack of inclusion of residents could be that local authorities managed their interests. Moreover, shippers seldom contribute to the studies, which is something of a paradox since they are often the ones who control the deliveries. Thus, in their purchase of the logistics service, shippers are commonly the ones placing demands on e.g. delivery service such as delivery times. Furthermore, the UCC operators are neglected when it comes to involvement in the research studies. One explanation could be that some researchers are not studying actual cases; if the actual UCCs do not exist, neither do their operators. In future studies, a greater emphasis ought to be directed towards how the affected stakeholders can be more involved.

\section{Gaps in Design of distribution structures}

A number of articles point at the importance of considering several aspects regarding selection of location for the UCC. By combining these, the list of aspects to include becomes rather long. Indeed, the design of the distribution structure can be viewed as "optimal", depending on which aspects are considered. It is especially important to consider multiple aspects, since a UCC affects a larger distribution system. There is a lack of studies that take a holistic approach and include all these aspects. When only narrow focuses are utilised, the risk for sub-optimisation increases. More holistic studies can also shed light on factors such as the importance of different aspects in different situations, guiding which aspects are of the most relevance to include in future studies.

\section{Gaps in Design of transport resources}

Although the change in fuel used was addressed in many articles, the focus was foremost on the need to change vehicles and fuel in order to respond to environmental challenges, and how this influences vehicle size. No article actually elaborated on the challenges that a change in fuel may prompt, such as the design of an electric network for vehicles in the city, the way the technology shift influences LSPs (through changes related to service and fuelling of the vehicles), or the way electricity is produced.

The alternative transport modes suggested in the reviewed articles are not extraordinary, such as the use of cable railway or drones. One uncommon mode, is the use of underground 
distribution systems (Boerkamps et al., 2000). One explanation to this could be that the costs associated with such extraordinary modes often are very high. The two most common alternative modes of transport in the reviewed articles are bikes (outbound transport) and rail (inbound transport). However, only a few articles have studied these modes, and often only as one isolated test. Therefore, further investigation of the potential of including bikes and rail in a UCC solution in terms of costs, environmental and social aspects, and the wider implications for stakeholders and related activities is needed to address this gap.

\section{Gaps in Environmental and Social considerations}

The studied articles seldom consider the triple-bottom-line (3BL). This gap in research has also been highlighted by Browne et al. (2007) and Staricco and Brovarone (2016). Later studies have started to pay more attention to the 3BL, such as the study by Handoko et al. (2016). Rao et al. (2015) considered economic, social, and environmental aspects in their optimisation model addressing preferable UCC locations. Also, Li et al. (2016) optimised both the minimisation of $\mathrm{CO}_{2}$ and costs. By highlighting the environmental and social benefits for each stakeholder, arguments why they should be a part of a UCC solution can be revealed. This especially applies to the local authorities, which possibly benefit the most by achieving a more attractive city with fewer freight vehicles.

Only three articles discussed the environmental or societal effects in terms of external costs. Bakos et al. (2012) mentioned that external costs should be included in models. Alessandrini et al. (2012) calculated external costs and suggested that the government can use the monetary savings to provide incentives for LSPs to use the UCC. Estrada et al. (2017) included external cost in their mathematical model. Calculating the environmental and social effects in terms of monetary value can be used as an argument supporting why stakeholders should be part of a UCC solution. Calculating costs with regard to the $3 \mathrm{BL}$ is a key area for further research to fully consider and understand the trade-offs, as well as synergies, between these areas. Furthermore, by using external costs, the results from different city logistics initiatives can be compared more easily.

\section{Gaps in Economic considerations}

Although the economic aspects of UCCs can be critical for the longevity of the initiatives, only a few articles actually addressed this issue in depth. There is a need for research to target how to finance these initiatives as well as how to design successful business models for UCC solutions. When it is possible to calculate the benefits in monetary value, companies can put that in relation to the cost of participating in a UCC. By further examining these aspects and investigating how the costs and benefits affect stakeholders, arguments supporting why different stakeholders should participate can be made clear.

Another important aspect is who should pay for the UCC since economic viability is a major barrier to attaining longevity. As UCC services often are viewed as the enabling factor, it was surprising that very few articles addressed these services, and if so without an in-depth elaboration. This points to a gap in the literature, as little knowledge is to be found with regard to potential services, service needs, who the potential customers are, and the potential customers' willingness to pay.

Economies of scale are often mentioned but seldom explained in detail or calculated. Multiple articles (e.g. Lin et al., 2014; Allen et al., 2014) stated that it is important to attract a high enough number of users of a UCC and reach a sufficiently high throughput of goods.

Economies of scale can thereby be gained for both LSPs and UCC operators. However, it is often only mentioned in vague qualitative terms, and very seldom are threshold values 
investigated. This points to an important knowledge gap, for both practitioners and researchers.

\section{Gaps outside the identified categories}

Gaps and further research needs have also been identified in terms of methodology and in terms of areas that have been inadequately addressed to be qualified as a category or theme.

\section{An area in need of the logistics management perspective}

It is interesting to note that almost half of the articles in the review were published in transport journals and only a few appeared in logistic management journals. Despite Dablanc (2005) being early to note that this narrowed transport focus is one reason behind the failures of UCCs, the literature still approaches this initiative from a transport perspective. While city logistics have been considered in logistic management journals to a large extent (e.g. Lagorio et al., 2016), articles focusing on UCCs have not. Since city logistics is undergoing rapid development and UCCs are one of the more studied initiatives, logistic management journals ought to focus on this initiative to a larger extent. We argue that a UCC is dependent on logistic management, since several common failures of UCCs can be traced to the lack of consideration of more logistic management-oriented aspects, such as consideration to total logistics costs and benefits analysis, awareness of the delivery services aspect, collaboration, and coordination between stakeholders in the logistics system.

\section{Lack of research based on primary data}

Only 19 of the reviewed articles used primary data. One limitation with secondary data is that it is not produced for the actual study but for other purposes and, thereby, answers other demands. Case studies were the second most-used method in the articles. However, the case studies were often not based on primary data, but rather on previous reports and general traffic data, pointing to another gap: more primary empirical studies are needed in order to both have representative data and describe cases more in depth, which could lead to further understanding of UCCs.

Some countries, such as Italy, Great Britain, Belgium, and the Netherlands, are overrepresented in terms of empirical data. This points to the need for empirical research studies in other countries and continents beside Europe.

\section{Journal publication is lacking}

Only 56 articles within the field were identified. The snowball approach showed that, in many articles, more than half of the references were reports or conference proceedings, not academic journal articles. Thus, the research results are more likely not to appear when doing regular literature searches in academic databases. This is a distinguishing feature of this research area within logistics. We argue that researchers within the field need to publish their results in journals to a much larger extent. Increased journal publication can spread the research, increase its visibility, and provide knowledge for other researchers within the city logistics and urban transport area. Another benefit of increased journal publication is that research targeting the challenges of urban transport can become more integrated into logistics and transport research. A third benefit is that an increased focus on journal publication could increase demands that the research considers theoretical perspectives more clearly. Even if some articles mention, for example, resource dependency, the need for coordination, and the large number of stakeholders, none of the articles have applied established theories, even though several theories, such as the resource-based view, resource-dependence theory, systems theory, stakeholder theory, network theory, or coordination theory would support them. 


\section{Lack of research on ICT and ITS}

Information and communication technology (ICT), intelligent transport systems (ITS), and digitalization can have great potential for applications in transport management to exploit the transport system in more efficient and coordinated ways. Despite these potentials, the use of this modern information technology is very seldom addressed in the UCC literature.

\section{Lack of consideration to warehouse management?}

"What happens in the UCC?", meaning what types of activities are being performed and how these activities support the services a UCC can provide, was an area only very superficially addressed in the articles. Although Crainic et al. (2004) put forward the question of consolidation as a central issue in the design of UCC solutions, few articles provided any deeper insights regarding how to do this. Does the literature on warehouse management cover this gap or do new challenges arise when the roles and responsibilities between actors change as is the case of UCCs?

\section{Conclusions, implications and limitations}

The structured literature review on journal articles focusing on UCCs reveals a limited and, at the same time, fragmented research area; only 56 relevant articles were identified that covered several disciplines and topics. Considering that no article was published prior to 2000 and that more than half of the articles were dated 2014 or later, it is clear that research within the UCC field is on the rise. Through the content analysis, five categories were identified: stakeholders, design of distribution structure, design of transport resources, environmental and social considerations, and economic considerations.

\section{Implications for research and research agenda}

Taking a focused scope on UCC initiatives resulted in the identification of new research issues, forming the basis for the suggested research agenda. For example, why are modern information technology topics seldom considered within UCC initiatives, as opposed to the larger city logistics area? Furthermore, the narrower scope applied in the present review has resulted in the identification of new gaps, such as the lacking environmental and social considerations and the need for more focus on the financial aspects.

Environmental and social considerations need to be truly present in the studies, not only used as a reason for taking action but instead to investigate its consequences. When discussing UCCs, environmental and social considerations are often taken for granted. It is important to also consider the synergies and trade-offs in the 3BL and thereby include environmental, social, and financial aspects. Research on UCCs often considers some aspects but seldom all of them simultaneously. Quantification of external costs could be one way to address this in future research.

Even if financial aspects are considered, research seldom targets how a UCC can generate revenue. UCC services can be viewed as the most enabling aspect for a UCC to generate revenue. However, these services are seldom investigated in detail or related to the interest and willingness to pay from the perspective of different stakeholders. Furthermore, economies of scale are viewed as a prerequisite for a UCC. However, very few studies provide any practical guidance for the system development with regard to the scales necessary for viability.

However, as UCC initiatives are an important part of city logistics, it is not surprising that similarities are also found between the present study and, for example, the one by Lagorio et 
al. (2016) about the need for more research targeting ways of stakeholder collaboration, lack of primary data, and the need for a holistic approach.

Based on the findings made, a call for research that goes into detail on innovative forms of stakeholder collaboration in UCC initiatives is in order. Inspiration ought to be found from the literature on e.g. private-public partnerships, that is, the involvement of private companies in the local transport planning process (e.g. Browne and Lindholm, 2013) and among viable UCC initiatives as the development of new organizational forms is singled out as a critical factor for viable business models for UCCs (Björklund et al., 2017).

We also call for more extensive use of primary data to increase our understanding of UCCs. The overrepresentation of empirical data from some countries calls for research in other geographical contexts, as regulations, taxes etc. can vary greatly among countries. In addition to this, aiming for more journal publications as a complement to today's research reports and conference proceedings can in the long run increase the dissemination of results to the research community as well as increasing the research quality of the studies made.

The need for taking a more holistic approach is already expressed in city logistics (such as the need to include the entire supply chain) and in urban transport (the need to integrate passenger and freight transport). However, the focused scope of this study gave insights to the need to consider a more holistic approach in almost every category identified, from not including the view from affected stakeholders to lacking 3BL consideration. Researchers need to view research on UCC more holistically and consider the impact on the entire system, not only its parts. Future research must at least acknowledge the limitations of their studies and reflect on the consequences of these limitations.

Finally, it is time to acknowledge that UCC is more than a transport management area. For the initiative to reach viability and achieve its full potential, there is a need to address these initiatives from more than a transport management perspective. However, a tendency can already be seen in the latest articles published, as these have a clearer focus on the business opportunities and have more extensively been targeting soft and management-oriented aspects.

\section{Implications for practitioners}

The present study has a significant impact on several of the stakeholders mentioned in the literature, including receivers, local authorities, and LSPs. The review of the literature shows that practitioners have a vital role in research targeting UCCs. To address the need for more primary data, the roles of stakeholders might need to change to not only contributing with information they already have but also to supporting researchers in the collection of data. The present study highlights the importance of more research with a focus on collaborating and organising the stakeholders in these initiatives. Thus, apart from talking about the importance of collaboration, shared actions, and responsibilities, research must also contribute with guidelines and tools on how this can be done. Furthermore, this review points to the importance of larger consideration to some stakeholder groups, especially suppliers and UCC operators, in future research.

Surprisingly few of the articles reviewed described how stakeholders have taken an active part and contributed with information to the research studies. Furthermore, many articles do not clarify for which stakeholders the managerial or practical implications are directed, if these implications are considered at all. As the need for targeting this objective in future research is addressed, an indirect effect will be to give much clearer guidance to practitioners. 
Furthermore, as researchers to a larger extent include stakeholders and reach the users, a fuller understanding of what the problem really is will increase.

By identifying the lack of logistic management studies, we have shed light on areas in which practitioners "have work to do", such as collaborations and the task to design revenue models. Furthermore, this study summarises different areas in which a practical contribution is stated. Important practical contributions can be found in further examination of threshold values in terms of users and throughput of goods that are needed to attain longevity in UCCs.

\section{Limitations}

Similar to any research study, the present study has its limitations. Some of the most central limitations regard the selection criteria used in the identification of articles. The authors decided to make this systematic literature review (SLR) largely inspired by the practice of earlier SLRs within the logistics and supply chain management field. In addition, the authors only searched for academic journal articles. This can be seen as a limitation, since much research can be found in conference proceedings and reports. Furthermore, only English articles were used due to the language limitations of the authors. The authors are researchers within the field of city logistics and are, therefore, aware of the early consideration and implementation of UCCs in countries like France and Germany. There is a risk that this review missed central research published with regard to these early initiatives if published in languages other than English.

Using an inductive approach to identify common categories and themes is a well-applied methodology for SLRs within the logistics field. However, one can always question to what extent the authors have been able to capture and describe the area in review, and if any important category or theme has been missed. There are likely as many ways to categorise a research area as there are ways to cut a cake, with some ways more suitable than others. We argue that what is most important is not the categories and themes themselves, but rather that they together summarise a research area and provide a useful and complete overview of the field. Furthermore, some findings discovered along the way further support our inductively identified categories, such as our theme "location of UCC(s)" in line with the statement by Crainic et al. (2004) suggesting where to perform the consolidation of goods as a very central question in the design of UCC solutions.

\section{Acknowledgement}

We thank the Swedish Energy Agency for financing the project "Economically viable urban consolidation centres for energy efficient and effective city distribution", in which this paper is a part. 


\section{References}

Alessandrini, A., Site, P.D., Filippi, F. and Salucci, M.V. (2012), "Using rail to make urban freight distributionmore sustainable ", European Transport - Trasporti Europei, pp. 1-17.

Allen, J., Browne, M. and Holguín-Veras, J. (2015), "Sustainability strategies for city logistics". In A. Mckinnon, M. Browne, M. Piecyk and A. Whiteing (eds.) Green logistics - Improving the environmental sustainability of logistics, 3 ed. Kogan Page: London, pp. 293-316.

Allen, J., Browne, M., Woodburn, A. and Leonardi, J. (2012), "The Role of Urban Consolidation Centres in Sustainable Freight Transport", Transport Reviews, Vol. 32 No. 4, pp. 473-490.

Allen, J., Browne, M., Woodburn, A. and Leonardi, J. (2014), "A review of urban consolidation centres in the supply chain based on a case study approach", Supply Chain Forum, Vol. 15 No. 4, pp. $100-112$.

Ambrosini, C., Gonzalez-Feliu, J.B. and Toilier, F. (2013), "A design methodology for scenarioAnalysis in urban freight modelling", European Transport - Trasporti Europei, pp. 1-22.

Awasthi, A. and Chauhan, S.S. (2012), "A hybrid approach integrating Affinity Diagram, AHP and fuzzy TOPSIS for sustainable city logistics planning", Applied Mathematical Modelling, Vol. 36 No. 2, pp. 573-584.

Awasthi, A., Chauhan, S.S. and Goyal, S.K. (2011), "A multi-criteria decision making approach for location planning for urban distribution centers under uncertainty", Mathematical and Computer Modelling, Vol. 53 No. 1/2, pp. 98-109.

Bakos, A., Bóna, K. and Foltin, S. (2012), "The development of a complex city logistics cost model according to a multiple-stage gateway concept", Periodica Polytechnica Transportation Engineering, Vol. 40 No. 1, pp. 17-20.

Battaia, G., Faure, L., Marquès, G., Guillaume, R. and Montoya-Torres, J.R. (2014), "A methodology to anticipate the activity level of collaborative networks: The case of urban consolidation", Supply Chain Forum, Vol. 15 No. 4, pp. 70-82.

Benjelloun, A. and Crainic, T.G. (2009), "Trends, challenges, and perspectives in city logistics", Transportation and land use interaction, proceedings TRANSLU, Vol. 8, pp. 269-284.

Benjelloun, A., Crainic, T.G. and Bigras, Y. (2010), "Towards a taxonomy of City Logistics projects", Procedia - Social and Behavioral Sciences, Vol. 2 No. 3, pp. 6217-6228.

Björklund, M., Abrahamsson, M. and Johansson, H. (2017), "Critical factors for viable business models for urban consolidation centres", Research in Transportation Economics, Vol. 64, pp. 36-47.

Boerkamps, J.H.K., Van Binsbergen, A.J. and Bovy, P.H.L. (2000), "Modeling behavioral aspects of urban freight movement in supply chains", Transportation Research Record, Vol. 1725, pp. 1725 .

Browne, M., Allen, J. and Leonardi, J. (2011), "Evaluating the use of an urban consolidation centre and electric vehicles in central London", IATSS Research, Vol. 35 No. 1, pp. 1-6.

Browne, M., Sweet, M., Woodburn, A. and Allen, J. (2005), "Urban Freight Consolidation Centres Final Report", Transport Studies Group.

Browne, M., Woodburn, A. and Allen, J. (2007), "Evaluating the potential for urban consolidation centres", European Transport - Trasporti Europei, Vol. 35, pp. 46-63.

Bryman, A. and Bell, E. (2015), Business research methods Oxford University Press, Oxford.

Carter, C., R. and Liane Easton, P. (2011), "Sustainable supply chain management: evolution and future directions", International Journal of Physical Distribution \& Logistics Management, Vol. 41 No. 1, pp. 46-62.

Cattaruzza, D., Absi, N. and Feillet, D. (2016), "The Multi-Trip Vehicle Routing Problem with Time Windows and Release Dates", Transportation Science, Vol. 50 No. 2, pp. 676-693.

Cerutti, A.K., Contu, S., Ardente, F., Donno, D. and Beccaro, G.L. (2016), "Carbon footprint in green public procurement: Policy evaluation from a case study in the food sector", Food Policy, Vol. 58, pp. 82-93.

Chen, Q., Lin, J. and Kawamura, K. (2012), "Comparison of Urban Cooperative Delivery and Direct Delivery Strategies", Transportation Research Record: Journal of the Transportation Research Board, Vol. 2288, pp. 28-39. 
Cherrett, T., Allen, J., Mcleod, F., Maynard, S., Hickford, A. and Browne, M. (2012), "Understanding urban freight activity - key issues for freight planning", Journal of Transport Geography, Vol. 24, pp. 22-32.

Cherrett, T., Dickinson, J., Mcleod, F., Sit, J., Bailey, G. and Whittle, G. (2017), "Logistics impacts of student online shopping - Evaluating delivery consolidation to halls of residence", Transportation Research Part C: Emerging Technologies, Vol. 78, pp. 111-128.

Crainic, T.G., Ricciardi, N. and Storchi, G. (2004), "Advanced freight transportation systems for congested urban areas", Transportation Research Part C: Emerging Technologies, Vol. 12 No. 2, pp. 119-137.

Crowther, M.A. and Cook, D. J. (2007), "Trials and tribulations of systematic reviews and meta analyses", ASH Education Program Book 2007, Vol. 1, pp. 493-497.

Dablanc, L. (2005), "French strategic approach to urban consolidation.", In 1st BESTUFS II Workshop Thematic focus: Approaches to Urban Consolidation: concepts and experiences, London.(http://www.bestufs.net/download/Workshops/BESTUFS_II/London_Jan05/BESTUF S_London_Jan05_Dablanc_INRETS.pdf).

Dablanc, $\bar{L}$. (2007), "Goods transport in large European cities: Difficult to organize, difficult to modernize", Transportation Research Part A: Policy and Practice, Vol. 41 No. 3, pp. 280-285.

Danielis, R., Rotaris, L. and Marcucci, E. (2010), "Urban freight policies and distribution channels: a discussion based on evidence from Italian cities", European Transport - Trasporti Europei, Vol. 46, pp. 114-146.

Dell'olio, L., Moura, J.L., Ibeas, A., Cordera, R. and Holguin-Veras, J. (2017), "Receivers' willingnessto-adopt novel urban goods distribution practices", Transportation Research Part A: Policy and Practice, Vol. 102, pp. 130-141.

Denyer, D. and Tranfield, D. (2009), "Producing a Systematic Review", in A.D. Buchanan and A. Bryman (eds.) The SAGE Handbook of Organizational Reseach Methods. SAGE Publications Ltd: London.

Durach, C.F., Kembro, J. and Wieland, A. (2017), "A new paradigm for systematic literature reviews in supply chain management", Journal of Supply Chain Management, Vol. 53 No. 4, pp. 67-85.

Escuín, D., Millán, C. and Larrodé, E. (2012), "Modelization of Time-Dependent Urban Freight Problems by Using a Multiple Number of Distribution Centers", Networks and Spatial Economics, Vol. 12 No. 3, pp. 321-336.

Estrada, M. and Roca-Riu, M. (2017), "Stakeholder's profitability of carrier-led consolidation strategies in urban goods distribution", Transportation Research Part E: Logistics and Transportation Review, Vol. 104, pp. 165-188.

Finnegan, C., Finlay, H., O'mahony, M. and O'sullivan, D. (2005), "Urban freight in dublin city center, Ireland: Survey analysis and strategy evaluation", Transportation Research Record, No. 1906, pp. 33-41.

Gammelgaard, B. (2015), "The emergence of city logistics: the case of Copenhagen's Citylogistik-kbh", International Journal of Physical Distribution \& Logistics Management, Vol. 45 No. 4, pp. 333351.

Gianessi, P., Alfandari, L., Létocart, L. and Wolfler Calvo, R. (2016), "The Multicommodity-Ring Location Routing Problem", Transportation Science, Vol. 50 No. 2, pp. 541-558.

Gimenez, C. and Tachizawa, E.M. (2012), "Extending sustainability to suppliers: a systematic literature review", Supply Chain Management: An International Journal, Vol. 17 No. 5, pp. 531-543.

Gonzalez-Feliu, J., Malhéné, N., Morganti, E. and Morana, J. (2014a), "The deployment of city and area distribution centers in France and Italy: Comparison of six representative models", Supply Chain Forum, Vol. 15 No. 4, pp. 84-99.

Gonzalez-Feliu, J., Salanova Grau, J.-M. and Beziat, A. (2014b), "A location-based accessibility analysis to estimate the suitability of urban consolidation facilities", International Journal of Urban Sciences, Vol. 18 No. 2, pp. 166-185.

Handoko, S.D., Lau, H.C. and Cheng, S.-F. (2016), "Achieving Economic and Environmental Sustainabilities in Urban Consolidation Center With Bicriteria Auction", IEEE Transactions on Automation Science and Engineering, Vol. 13 No. 4, pp. 1471-1479. 
Hoejmose, S.U. and Adrien-Kirby, A.J. (2012), "Socially and environmentally responsible procurement: A literature review and future research agenda of a managerial issue in the 21st century", Journal of Purchasing and Supply Management, Vol. 18 No. 4, pp. 232-242.

Holguín-Veras, J., Ozbay, K., Kornhauser, A., Brom, M., Iyer, S., Yushimito, W., ....and Silas, M. (2011), "Overall Impacts of Off-Hour Delivery Programs in New York City Metropolitan Area", Transportation Research Record: Journal of the Transportation Research Board, Vol. 2238, pp. 68-76.

Janjevic, M., Kaminsky, P. and Ndiaye, A.B. (2013), "Downscaling the consolidation of goods-state of the art and transferability of micro-consolidation initiatives", European Transport - Trasporti Europei, No. 54, pp. 1-23.

Janjevic, M. and Ndiaye, A. (2017), "Investigating the theoretical cost-relationships of urban consolidation centres for their users", Transportation Research Part A: Policy and Practice, Vol. 102, pp. 98-118.

Ji, Y., Qu, S. and Yu, Z. (2017), "Bi-level multi-objective optimization model for last mile delivery using a discrete approach", Journal of Difference Equations and Applications, Vol. 23 No. 1/2, pp. 179-190.

Johansson, H. and Björklund, M. (2017), "Urban consolidation centres: retail stores' demands for UCC services", International Journal of Physical Distribution \& Logistics Management, Vol. 47 No. 7, pp. 646-662.

Lagorio, A., Pinto, R. and Golini, R. (2016), "Research in urban logistics: a systematic literature review", International Journal of Physical Distribution \& Logistics Management, Vol. 46 No. 10, pp. 908-931.

Lebeau, P., Macharis, C., Van Mierlo, J. and Maes, G. (2013), "Implementing electric vehicles in urban distribution: A discrete event simulation ", World Electric Vehicle Journal, Vol. 6 No. 1, pp. $38-47$.

Lebeau, P., Verlinde, S., Macharis, C. and Van Mierlo, J. (2017), "How can authorities support urban consolidation centres? A review of the accompanying measures", Journal of Urbanism: International Research on Placemaking and Urban Sustainability, Vol. 10 No. 4, pp. 468-486.

Li, H., Yuan, J., Lv, T. and Chang, X. (2016), "The two-echelon time-constrained vehicle routing problem in linehaul-delivery systems considering carbon dioxide emissions", Transportation Research Part D: Transport and Environment, Vol. 49, pp. 231-245.

Lin, J., Chen, Q. and Kawamura, K. (2014), "Sustainability SI: Logistics Cost and Environmental Impact Analyses of Urban Delivery Consolidation Strategies", Networks and Spatial Economics, Vol. 16 , pp. 227-253.

Lindholm, M. and Browne, M. (2013), "Local Authority Cooperation with Urban Freight Stakeholders: A comparison of Partnership Approaches", European Journal of transport and infrastructure research, Vol. 13 No. 1, pp. 20-38.

Mangiaracina, R., Song, G. and Perego, A. (2015), "Distribution network design: a literature review and a research agenda", International Journal of Physical Distribution \& Logistics Management, Vol. 45 No. 5, pp. 506-531.

Marcucci, E. and Danielis, R. (2007), "The potential demand for a urban freight consolidation centre", Transportation, Vol. 35 No. 2, pp. 269-284.

Meixell, M.J. and Luoma, P. (2015), "Stakeholder pressure in sustainable supply chain management", International Journal of Physical Distribution \& Logistics Management, Vol. 45 No. 1/2, pp. 69-89.

Morganti, E. and Gonzalez-Feliu, J. (2015), "City logistics for perishable products. The case of the Parma's Food Hub", Case Studies on Transport Policy, Vol. 3 No. 2, pp. 120-128.

Muñoz-Villamizar, A.F., Montoya-Torres, J.R. and Herazo-Padilla, N. (2014), "Mathematical Programming Modeling and Resolution of the Location-Routing Problem in Urban Logistics", Ingenieria y Universidad, Vol. 18 No. 2, pp. 271-289.

Muñuzuri, J., Larrañeta, J., Onieva, L. and Cortés, P. (2005), "Solutions applicable by local administrations for urban logistics improvement", Cities, Vol. 22 No. 1, pp. 15-28.

Nordtømme, M.E., Bjerkan, K.Y. and Sund, A.B. (2015), "Barriers to urban freight policy implementation: The case of urban consolidation center in Oslo", Transport Policy, Vol. 44, pp. 179-186. 
Olsson, J. and Woxenius, J. (2014), "Localisation of freight consolidation centres serving small road hauliers in a wider urban area: barriers for more efficient freight deliveries in Gothenburg", Journal of Transport Geography, Vol. 34, pp. 25-33.

Paddeu, D. (2017), "The Bristol-Bath Urban freight Consolidation Centre from the perspective of its users", Case Studies on Transport Policy, Vol. 5 No. 3, pp. 483-491.

Paddeu, D., Fancello, G. and Fadda, P. (2017), "An experimental customer satisfaction index to evaluate the performance of city logistics services", Transport, Vol. 32 No. 3, pp. 262-271.

Pamučar, D., Gigović, L., Ćirović, G. and Regodić, M. (2016), "Transport spatial model for the definition of green routes for city logistics centers", Environmental Impact Assessment Review, Vol. 56, pp. 72-87.

Pilbeam, C., Alvarez, G. and Wilson, H. (2012), "The governance of supply networks: a systematic literature review", Supply Chain Management: An International Journal, Vol. 17 No. 4, pp. 358-376.

Quak, H., Balm, S. and Posthumus, B. (2014), "Evaluation of City Logistics Solutions with Business Model Analysis", Procedia - Social and Behavioral Sciences, Vol. 125, pp. 111-124.

Rao, C., Goh, M., Zhao, Y. and Zheng, J. (2015), "Location selection of city logistics centers under sustainability", Transportation Research Part D: Transport and Environment, Vol. 36, pp. 2944.

Saenz, M.J. and Koufteros, X. (2015), "Special issue on literature reviews in supply chain management and logistics", International Journal of Physical Distribution \& Logistics Management, Vol. 45 No. $1 / 2$.

Skjoett-Larsen, T. (2000), "European logistics beyond 2000", International Journal of Physical Distribution \& Logistics Management, Vol. 30 No. 5, pp. 377-387.

Sopha, B.M., Asih, A.M., Pradana, F.D., Gunawan, H.E. and Karuniawati, Y. (2016), "Urban distribution center location", International Journal of Engineering Business Management, Vol. 8 , pp. 1-10.

Staricco, L. and Brovarone, E.V. (2016), "The spatial dimension of cycle logistics", Tema. Journal of Land Use, Mobility and Environment, Vol. 9 No. 2, pp. 173-190.

Teo, J., Taniguchi, E. and Qureshi, A. (2015), "Evaluation of Urban Distribution Centers Using Multiagent Modeling with Geographic Information Systems", Transportation Research Record, No. 2478, pp. 35-47.

Touboulic, A. and Walker, H. (2015), "Theories in sustainable supply chain management: a structured literature review", International Journal of Physical Distribution \& Logistics Management, Vol. 45 No. $1 / 2$, pp. 16-42.

Tozzi, M., Corazza, M.V. and Musso, A. (2014), "Urban goods movements in a sensitive context: The case of Parma", Research in Transportation Business \& Management, Vol. 11, pp. 134-141.

Tranfield, D., Denyer, D. and Smart, P. (2003), "Towards a methodology for developing evidenceinformed management knowledge by means of systematic review", British journal of management, Vol. 14 No. 3, pp. 207-222.

Triantafyllou, M.K., Cherrett, T.J. and Browne, M. (2014), "Urban freight consolidation centers case study in the UK retail sector", Transportation Research Record, Vol. 2411, pp. 34-44.

United Nations Department of Economic and Social Affairs (2014), World Urbanization Prospects: The 2014 Revision, Highlights [online]. http://esa.un.org/unpd/wup/highlights/wup2014highlights.pdf [Access date: 29 May 2017].

Van Rooijen, T. and Quak, H. (2010), "Local impacts of a new urban consolidation centre - the case of Binnenstadservice.nl", Procedia - Social and Behavioral Sciences, Vol. 2 No. 3, pp. 5967-5979.

Ville, S., Gonzalez-Feliu, J. and Dablanc, L. (2013), "The Limits of Public Policy Intervention in Urban Logistics: Lessons from Vicenza (Italy)", European Planning Studies, Vol. 21 No. 10, pp. 15281541.

Wolpert, S. and Reuter, C. (2012), "Status Quo of City Logistics in Scientific Literature", Transportation Research Record: Journal of the Transportation Research Board, Vol. 2269, pp. 110-116. 
Wong, C.Y., D., Wong, C.W.Y. and Boon-Itt, S. (2015), "Integrating environmental management into supply chains", International Journal of Physical Distribution \& Logistics Management, Vol. 45 No. $1 / 2$, pp. $43-68$

Yang, W., Cheong, T. and Song, S.H. (2015), "A Multiperiod Vehicle Lease Planning for Urban Freight Consolidation Network", Mathematical Problems in Engineering, Vol. 2015, pp. 1-15.

Zhou, Y. and Wang, X. (2014), "Decision-Making Process for Developing Urban Freight Consolidation Centers: Analysis with Experimental Economics", Journal of Transportation Engineering, Vol. 140 No. 2, pp. 1-7.

Zunder, T. and Ibanez, J.N. (2004), "Urban freight logistics in the European Union", European Transport $\backslash$ Trasporti Europei, Vol. 28, pp. 77-84.

Österle, I., Aditjandra, P.T., Vaghi, C., Grea, G. and Zunder, T.H. (2015), "The role of a structured stakeholder consultation process within the establishment of a sustainable urban supply chain", Supply Chain Management: An International Journal, Vol. 20 No. 3, pp. 284-299. 
$\underline{\text { Tables }}$

Table 1:

\begin{tabular}{lll}
\hline & \multicolumn{1}{c}{ Search terms } & \\
\hline Urban distribution cent* & Urban distribution depot* & City terminal* \\
City distribution cent* & City logistic* cent* & Urban terminal* \\
Urban freight platform* & Urban logistic* cent* & Urban consolidation cent* \\
$\begin{array}{l}\text { City freight platform* } \\
\text { City distribution depot* }\end{array}$ & $\begin{array}{l}\text { City transhipment depot* } \\
\text { Urban transhipment } \\
\text { depot* }\end{array}$ & $\begin{array}{l}\text { City consolidation cent* } \\
\text { Urban transhipment cent* }\end{array}$ \\
$\begin{array}{ll}\text { City transhipment cent* } \\
\text { Urban consolidation } \\
\text { platform* }\end{array}$ & $\begin{array}{l}\text { Urban freight cent* } \\
\text { City consolidation } \\
\text { platform* }\end{array}$ & $\begin{array}{l}\text { City freight cent* } \\
\text { Freight consolidation cent* }\end{array}$ \\
\hline
\end{tabular}

Table 2:

\begin{tabular}{ll}
\hline Journal & No. \\
\hline Transportation Research Record: Journal of the Transportation Research Board & 6 \\
European Transport & 6 \\
Supply Chain Forum: An International Journal & 3 \\
Transportation Research, part A & 3 \\
Case Studies on Transport Policy & 2 \\
Environmental Impact Assessment Review & 2 \\
Journal of Transport Geography & 2 \\
Mathematical and Computer Modelling & 2 \\
Networks and Spatial Economics & 2 \\
Transportation Research, part C & 2 \\
Transportation Research Part D, Transport and Environment & 2 \\
Applied Mathematical Modelling & 1 \\
Cities & 1 \\
European Planning Studies & 1 \\
Hindawi Publishing Corporation & 1 \\
IATSS Research & 1 \\
IEEE Transactions on Automation Science and Engineering & 1 \\
Ingenieria y Universidad & 1 \\
International journal of Engineering Business Management & 1 \\
International Journal of Physical Distribution \& Logistics Management & 1 \\
International Journal of Urban Sciences & 1 \\
Journal of Difference Equations and Applications & 1 \\
Journal of Transportation Engineering & 1 \\
Journal of Urbanism: International Research on Placemaking and Urban & \\
Sustainability & 1 \\
Research in Transportation Business and Management & 1 \\
Research in Transportation Economics & 1 \\
Supply Chain Management: An International Journal & 1 \\
TeMA Journal of land use mobility and environment & 1 \\
Transport & 1 \\
\hline
\end{tabular}




\begin{tabular}{lc}
\hline Transport Policy & 1 \\
Transport Reviews & 1 \\
Transportation & 1 \\
Transportation Research, Part E & 1 \\
Transportation Science & 1 \\
World Electric Vehicle Journal & 1 \\
\hline
\end{tabular}

\section{Table 3:}

\begin{tabular}{ll}
\hline Method & Number of articles \\
\hline Mathematic modelling & 29 \\
Case & 15 \\
Review & 7 \\
Conceptual & 4 \\
Experiment/laboratory & 1 \\
\hline
\end{tabular}

\section{Table 4:}

\begin{tabular}{ll}
\hline Type of empirical data & Number of articles \\
\hline Primary data & 14 \\
Secondary data & 34 \\
Both primary and secondary & 5 \\
No empirical data & 3 \\
\hline
\end{tabular}

Table 5:

\begin{tabular}{lll}
\hline Category & Theme & Papers \\
\hline Stakeholders & Mention stakeholders & $1,2,4,5,8,9,10,11,12,15,17,18$, \\
& & $19,20,23,24,25,28,29,31,33,34$, \\
& $35,36,37,39,42,44,45,46,47,48$, \\
& $49,50,51,52,53,54,55,56$ \\
& Stakeholder & $8,9,13,15,16,17,22,23,25,27,29$, \\
& collaboration in UCC & 35,36 \\
& initiatives & \\
Stakeholder & $4,5,8,9,10,11,13,14,15,16,17$, \\
& involvement/support in & $18,20,21,22,26,27,28,30,32,35$, \\
& research study & $36,37,40,45,46,47,51,54,55$ \\
& Practical contribution & $3,5,8,9,10,11,13,14,15,16,17$, \\
& & $18,20,22,23,27,28,29,30,33,34$, \\
Design of & & $35,36,37,40,44,45,46,47,48,49$, \\
distribution & & $50,51,52,53,54,55,56$ \\
structure & Localisation of UCC & $1,2,10,11,15,17,19,20,23,24,25$, \\
& & $29,31,34,37,42,49$ \\
& & \\
& & $1,2,4,5,11,15,17,18,19,24,33,50$
\end{tabular}


Design of transport Change in vehicle fuel resources

Economic considerations

Intermodal transports

Environmental and Driving forces

social

considerations

Economic
considerations

\section{Changes in}

environmental and

social dimensions

UCC as a cost driver or

reducer

\section{Economy of scale}

Who should finance
$2,5,6,13,14,16,18,22,24,26,28$, $29,31,32,33,35,37,38,39,42,44$, $45,47,52,53,55$

$2,6,16,24,28,44,52,55$

$3,5,8,9,10,11,13,14,15,16,17$, $19,20,22,23,25,26,27,28,29,30$, $32,33,34,35,36,37,40,44,45,46$, $47,48,49,50,51,52,53,54,55,56$ $3,4,5,8,9,10,11,13,14,16,17,18$, $20,22,23,28,29,30,31,32,33,34$, $35,36,37,39,40,42,44,49,53$

$2,3,4,8,9,10,11,14,15,16,17,18$, $19,20,22,23,25,27,28,29,30,31$, $32,33,34,35,36,37,38,39,40,41$, $42,45,46,47,48,49,50,51,52,53$, $54,55,56$

$14,15,16,18,20,22,27,29,31,37$, $39,40,47,48,52,53,54,55$

$3,8,9,11,12,14,15,16,18,19,22$, $23,24,25,26,27,28,29,30,32,33$, $35,36,37,41,44,45,46,47,48,51$, $52,53,54,55,56$ 